\title{
O RESSOAR DA CULTURA DO ABOIO NO FAZER ARTÍSTICO
}

\author{
EL RESONAR DE LA CULTURA DEL ABOIO EN EL HACER \\ ARTÍSTICO
}

\section{THE RESONATE OF THE ABOIO CULTURE BEHIND DOING ART}

\author{
Jessiara Menezes Lorena \\ César Lignelli
}

\begin{abstract}
RESUMO
O artigo apresenta características da cultura do aboio, a partir das pesquisas idealizadas por Mário de Andrade na Missão de Pesquisas Folclóricas em 1938, em diálogo com os autores Adriano Caçula Mendes e Maria Laura de Albuquerque Maurício. Discorre acerca da prática da atriz em sala de ensaio, com foco para exercícios e posturas corporais, que são estudados como potencializadores de uma tensão e atenção corporal, em prol de um corpo consciente e criativo em cena. A pesquisa prática é esmiuçada considerando conceitos de criadores como Jerzy Grotowski e Mario Biagini. Apresenta- se assim, um trabalho prático e teórico que partiu de cantos rurais de tradições brasileiras, os quais carregam peculiaridades dos seus fazedores, no intuito de investigar as especificidades e poéticas da artista que se coloca em processo de criação.
\end{abstract}

PALAVRAS-CHAVE: aboiar, canto, culturas brasileiras, processo de criação

\section{RESUMEN}

El artículo presenta las características de la cultura del aboio a partir de las investigaciones realizadas por Mário de Andrade en la Misión de Investigaciones del Folklore en 1983, en diálogo con los autores Adriano Caçula Mendes y Maria Laura de Albuquerque Maurício. Lo cual desarrolla la práctica de la actriz en la sala de ensayo con enfoque en ejercicios y posturas corporales, que se estudian como mejoradores de tensión y atención corporal, en favor de un cuerpo consciente y creativo en escena. La investigación práctica es estudiada en vista de los conceptos de creadores como Jerzy Grotowski y Mario Biagini. Se presenta el trabajo teóricopráctico que partió de los cantos rurales de tradiciones brasileñas, los cuales cargan las peculiaridades de sus agentes para estudiar las especificidades y poéticas de la artista en proceso de creación.

PALABRAS CLAVE: aboiar, canto, culturas brasileñas, proceso de creación

\footnotetext{
ABSTRACT

This article presents characteristics of the aboio culture through researches from Mário de Andrade in the Folkloric Research Mission in 1938, in dialogue with the authors Adriano Caçula Mendes and Maria Laura de
} 


\begin{abstract}
Albuquerque Maurício. It discusses the practice of the actress in a rehearsal room focusing on exercises and body postures that are studied as potentiator of the tension, and the body attention in favor of conscious and creative body in scene. The practical research is carefully investigated regarding author's concepts, such as Jerzy Grotowski and Mario Biagini. Is presented a theoretical-practical work that came from chants among Brazilian rural traditions, which carry peculiarities of their doers, in order to study the specificities and poetic of the artist in process of creation.
\end{abstract}

KEYWORDS: aboiar, song, brazilian cultures, creation process

$$
* * *
$$

\title{
Introdução
}

O presente artigo discorre sobre a cultura do aboio em diálogo com a sala de ensaio. Foca em alguns cantos de tradições brasileiras, que tangem os bois em diferentes lugares do país, como material poético de criação. Desse modo, a autora se coloca na sala de trabalho para investigar o corpo enquanto lugar potencializador de poéticas, movimentos, sons.

$\mathrm{O}$ artigo foi dividido em três etapas para maior entendimento do todo e do processo de criação e investigação prática. Na parte I 'Aboio' o texto foi direcionado para essa cultura e sua apresentação, com foco para definições e algumas abordagens. No item II 'Processo Criativo Investigativo' salientou-se a investigação iniciada na sala de ensaio e de que maneira se tornou material criativo. São observações pontuais de alguns exercícios, imagens e ações quer foram recorrentes ao longo da prática. Por fim, na etapa III 'Os aboios e suas reverberações na prática' o texto discorreu sobre como os aboios influenciaram o material poético criado pela atriz.

Os questionamentos que embasaram a prática foram: quais cantos são considerados tradicionais a partir do meio em que se vive? Como a prática pode ser conduzida através desta pesquisa que busca um aprofundamento desses cantos tradicionais? Que tipo de memória aliada a esse universo pode (re)viver no corpo? E, ainda, como friccionar essas informações com o processo criativo, tornando-as ação? 
I. Aboio

A expressão 'aboio', utilizada para denominar o som emitido pelos vaqueiros, possui também outros significados dentro das relações entre as culturas. Pode-se tornar vago se observado apenas como denominador de melodias mais livres, visto os processos de adaptações e desenvolvimentos que essa manifestação precisou passar para se manter viva. Assim, apresenta-se aqui alguns lugares de inserção e outras definições, a fim de refletir sobre o tema, questões sociais, culturais e econômicas que podem transpassar essa sonoridade e seus desdobramentos.

Segundo Adriano Caçula Mendes, o aboio é uma sonoridade com características melismáticas e se orienta por meio de glissandos, com pulso mais livre e ritmado. A melodia é composta por interjeições em seus finais, mediante poucas palavras ou apenas vogais. Os pontos de maior intensidade estão interligados ao ar que é retido nos pulmões. Desse modo, o autor acentua: "Em suma, possuem um perfil melódico que se funda sobre um canto que descansa sobre polos frequenciais" (MENDES, 2015, p. 23).

No dicionário, o termo aboio recebe a seguinte definição: "canto grave e monótono do vaqueiro ou pastor, geralmente sem palavras, para conduzir ou chamar o gado"1. Mário de Andrade, em seu livro 'As melodias do boi', diz o seguinte: "O aboio é um canto melancólico com que os sertanejos do Nordeste ajudam a marcha das boiadas. É antes uma vocalidade oscilante entre as vogais a e ô" (ANDRADE, 1987, p. 54).

Andrade define também, em seu 'Dicionário Musical Brasileiro', o verbo aboiar:

(V.I; S.m). O marroeiro (vaqueiro) conduzindo o gado nas estradas, ou movendo com ele nas fazendas, tem por costume cantar. Entoa um arabesco, geralmente livre de forma estrófica, destituído de palavras as mais das vezes, simples vocalizações, interceptadas quando senão por palavras interjectivas, "boi êh boi", boiato, etc. O ato de cantar assim chama de aboiar. Ao canto chama de aboio (ANDRADE, 1989, p. 1-2).

1 ABOIO. In: Dicionário Priberam da Língua Portuguesa. Lisboa, 2017. Disponível em: https://www.priberam.pt/dlpo/aboio. Acesso em: 27 jul. 2018 14:25 
As definições expostas colocam sempre o aboio como uma comunicação em si. Ele está em relação constante com o outro e detém características de uma melodia livre, visto as sonoridades que são vivenciadas em seus cantos. As vogais fazem parte de um movimento de ressonância, proporcionam uma abertura do aparelho fonador, em especial da glote, propiciando um som prolongado, sem quebras, como normalmente acontecem quando são inseridas consoantes. Aquele que canta está, assim, liberto para improvisar suas melodias.

A característica pessoal dentro do trabalho se insere muito naturalmente, mediante estas especificidades que a prática detém. Cabe ao marroeiro tanto a melodia quanto a maneira de conduzir a boiada, o que pode deixar muitas vezes o som monótono e melancólico. São os arabescos criados na lida diária que vão, gradativamente, compor a memória daqueles cantos e das pessoas que os carregam.

Ainda no mesmo livro, Andrade relata sobre uma carta recebida de Ascenso Ferreira, um poeta pernambucano que lhe escreveu sobre os aboios do Nordeste:

Eu deixei a questão do aboiado pro fim porque aqui a coisa fia mais fino. Primeiro que tudo aqui pelo Norte não há aboiado: há aboio! Porém ninguém será capaz de mandar-te nenhum. É um canto todo pessoal que varia de indivíduo prá indivíduo. [Nota a lápis, de Mário de Andrade: 'o que verifica a minha observação sobre o individualismo do canto brasileiro...'] Não tem palavras. É uma espécie de canto de padre na missa, quando faz aquelas voltas apenas com sons. Mesmo em Pernambuco quase que não há aboio. Só lá pro Sertão fundo: Jabotá, Cabrobó, Ouricuri, Exu. (...) Nos grandes núcleos sertanejos como Garanhuns, Caruaru, Pesqueira etc. aparece às vezes um vaqueiro aboiando mas não é coisa de se chegar e se encontrar quando se queira (ANDRADE, 1987, p. 54).

O aboio dentro desse patamar pessoal, pode ser um canto muito minucioso nascido do contato entre os vaqueiros e os bois, algo identificado no cotidiano dessas pessoas de uma maneira simples e artesanal. Percebe-se a dificuldade já naquela época, início do século XX, em se encontrar aboiadores que não estivessem no Sertão. Hoje em dia, as dificuldades são ainda maiores, 
visto a contemporaneidade e a consequente mecanização do trabalho no campo.

Quando o poeta pernambucano se refere ao aboio como algo que 'fia mais fino', ele expressa respeito e cuidado com esse tema, visto as especificidades de cada indivíduo que são apresentadas ao compor esses cantos. Dialoga com a artesania oral passada de geração em geração, que se desenvolve na lida diária das pessoas no campo. O individualismo acentuado por Andrade, como característica percebida nas manifestações brasileiras, demonstra carregar particularidades dos praticantes, dentro de uma gama de saberes que no geral definem uma cultura.

Acentua-se a potência da transmissão oral frente à sua resistência, sem perder características fundantes, dentre outras que surgem como uma maneira de detalhar a manifestação no intuito de produzir conhecimento, sentido e desejo, em diálogo com o momento vigente. Uma gama de saberes que é alimentada, paulatinamente, pelas individualidades e peculiaridades de cada um.

$\mathrm{O}$ arabesco pode ser uma imagem que suscite ao leitor algumas interpretações, uma possibilidade de abordagem musical e estética, visto os caminhos possíveis mediante seu aprofundamento. Neste caso musical, porque compreende características melódicas, com variações de frequência, duração e intensidade; e estética, pois abarca um caráter peculiar dentro dos cantos e partilha singularidades, as quais se intensificam - os arabescos pessoais - a favor de um todo, a manifestação enquanto cultura criadora, participativa e produtora de saberes.

Parte-se, assim, do movimento que, de tão singular, pode aparentar uma falta de precisão para um lugar amplo de trocas e diálogos dentro das práticas em que as composições singulares ampliam as possibilidades de desenvolvimento do todo e criam, por si só e em contato com o meio, uma ludicidade e especificidades comuns. 
Ascenso Ferreira ainda caracteriza o aboio como um canto sem palavras - 'é uma espécie de canto de padre na missa' - o que pode aproximar propriedades religiosas e ritualísticas à prática, por meio da comparação realizada. Não há, aqui, a pretensão de incorporar essas características como fundantes na abordagem feita, mas pretende-se dialogar com patamares que colocam o fazedor no lugar presente, em contato direto com o meio e à ação realizada.

As variações melódicas, particularizadas pela falta de palavras, propiciam uma liberdade ao praticante a partir das sonoridades que fazem sentido dentro daquela prática exercida, assim como em meio à escuta, que já vem estimulada desde os primeiros contatos com o ambiente e com os sons que os compõe. Isto posto, pode-se perceber a ressonância da transmissão oral nas singularidades de cada um e na maneira como é absorvida e apropriada como algo pessoal.

Segundo Maria Laura de Albuquerque Maurício, outra característica dos boiadeiros é que, na maioria das vezes, trabalham em grupos, ou duplas, existindo assim um sentimento de coletividade que perpassa o trabalho, já que um sempre pode contar com outro (MAURÍCIO, 2006).

Fora dos campos, o aboio assume um formato rimado, que pode vir carregado de uma forte crítica social, as chamadas toadas. Mendes coloca o seguinte acerca do tema:

Normalmente, Toada é um termo genérico que é utilizado, muitas vezes, como sinônimo do termo música pelos aboiadores. Na situação do Aboio de festivais competitivos e do espetáculo, é um termo mais específico utilizado para a representação dessas melodias incorporadas hibridamente de outros gêneros de improviso que recebem usualmente o nome de toadas de vaquejada. A palavra toada incorporou, principalmente, o significado atribuído pelos cantadores de viola para o termo. Foi chamado, por alguns aboiadores em campo, de aboios modernos. Observa-se aqui em operação aspectos da cultura oral, onde as divisões entre afazeres são bastante borradas, e por isso a flexibilidade entre aboiadores e cantadores de viola na troca de termos como a palavra toada, um afazer comum aos dois agentes de cultura (MENDES, 2015, p. 26).

A toada exprime também os sentimentos dos vaqueiros, como a estrofe de Zé da Luz que segue a baixo. Alguns assuntos recorrentes são: religiosidade 
(santos), a morte e a mulher. O heroísmo também percorre por entre os temas abordados, a coragem, o vigor físico, tudo atrelado ao trabalho, sempre em relação ao boi e o ambiente:

\begin{abstract}
Se no rompê da arvoráda,
$\mathrm{Na}$ frente de uma boiáda

Éra uma canto de aligría, Quando a tarde discambáva

Éra a prece qui eu rezáva,

Na hóra d'Ave María!

E o meu abóio se perdía

Pêlas quebrada das serra,

Cumo um saluço da terra,

Chorando a morte do dia!...
\end{abstract}

Zé da Luz ${ }^{2}$

O aboio amplia para uma dimensão sócio/econômica, ao passo que os cantadores de toadas procuram se especializar, por meio da linguagem poética dessas rimas e do uso de instrumentos. Mendes coloca em seu texto as observações destas diferenças realizadas pelos próprios aboiadores/cantadores, como propulsoras de renda por meio da cultura do vaqueiro. Expõe a facilidade dos cantadores em emitir o aboio tradicional, mesmo que alguns nunca o tenham praticado em relação aos animais nos pastos (MENDES, 2015).

O contato com a tradição vem, assim, por outras vias, em diálogo com a mercantilização contemporânea. Alguns já possuem uma iniciação que é completamente voltada para as toadas, inseridas dentro dos festivais e gravações de $\mathrm{Cds}$, lugares esses que podem vislumbrar uma renda por meio do canto. A diferença em relação aos aboiadores seria a de que muitos não são alfabetizados e não possuem, às vezes, um interesse pela métrica dos repentistas (MENDES, 2015).

A mulher aparece, neste contexto, de formas variadas: em relações afetuosas, em histórias de amor, em situações cotidianas e estereotipadas de uma maneira geral. Desse modo, dificilmente abre- se espaço para participação do gênero feminino no trabalho e compartilhamento de 
experiências relacionadas ao tema do aboio. O universo do aboio ainda é em sua maioria masculino, por mais que hoje em dia algumas mulheres já se insiram neste território com mais frequência, como por exemplo, nas toadas e nos festivais de aboios.

O aboio possui assim características coletivas de troca, subsídio e escuta. Os marroeiros atuam em grupo nos pastos, assim como nas rodas de vaqueiros e nas toadas. Em sua maioria, o diálogo parte de um corpo que se percebe, responde a seus anseios internos, suas vontades, improvisa com sonoridades soltas, relacionadas ao campo, aos animais, à sua percepção de todo esse universo em direção a outro corpo. Esse segundo, o que recebe, seja o corpo do boi ou do ser humano, de alguma maneira é afetado por esse chamado, ou pelas inquietações sociais e pessoais expressas nas rodas de aboios. Essa voz ressoa e provoca movimento, mudança, atua como veículo destas melodias pessoais, vestigiais e livres.

\section{Processo Criativo Investigativo}

A pesquisa partiu de questionamentos embasados na prática da atriz e propõe como direcionamento os diálogos entre a prática e a teoria, por via de um trabalho investigativo e criativo. Assim ela colocou-se na sala de ensaio para pesquisar sonoridades primeiramente experienciadas a partir das gravações da Missão de Pesquisas Folclóricas ${ }^{3}$.

Os três meses iniciais (setembro/outubro/novembro de 2015) foram em uma sala do Departamento de Artes Cênicas da UnB, com trabalhos práticos semanais. Em seguida, passou-se para outro espaço no Núcleo de Dança da UnB, onde ensaiou até o final do processo prático (junho de 2017).

Após o primeiro semestre de ensaio, aumentou-se a carga horária. Assim, de dois dias por semana, ela passou a trabalhar três vezes, com quatro horas diárias. Alguns intensivos foram realizados durante esse processo, todos os dias pela manhã. Como exemplo, em julho de 2016 a atriz trabalhou

\footnotetext{
3 A Missão de Pesquisas Folclóricas foi idealizada por Mário de Andrade e realizada com financiamento do Departamento de Cultura de São Paulo em 1938.
} 
duas semanas seguidas, quatro horas por dia. Direcionava, dessa forma, para algumas ações específicas ou temas, como ressonadores, os próprios aboios, contatos com os objetos de cena, entre outras especificidades que sentia dificuldade na hora da investigação.

Quando a prática estava centrada especificamente com os aboios, houve necessidade de explorar um espaço aberto, a fim de construir uma relação concreta com o meio, que envolvesse também uma experiência mais ampla a partir das ressonâncias corporais. Explorou-se, dessa maneira, alguns lugares da UnB e do Parque Olhos D’Água, localizado na Asa Norte em Brasília/DF (maio/junho/julho de 2016).

A pesquisa prática continuou na sala fechada, mas vez ou outra ela procurava experimentar esses locais abertos a partir das ações que desenvolvia (agosto de 2016 em diante). O que realmente parecia fazer mais sentido era aboiar por entre o espaço e jogar com os pontos fixos externos. $\mathrm{O}$ aboio iria em direção a quê? De que maneira dialogava com o espaço ao redor?

A relação com o ambiente externo fez toda diferença na pesquisa, dado os contatos que foram possíveis, tanto com o meio, quanto com o corpo em determinadas situações. Nos espaços abertos, a escuta necessitava estar duplamente atenta, visto a quantidade de informações que transpassavam a todo momento o ambiente. Dessa maneira, colocava necessariamente à prova a atenção e as tensões possíveis a partir desses contatos que diariamente passavam despercebidos aos ouvidos.

Os ensaios, de uma maneira geral, foram preparados com foco no alongamento, no aquecimento e na parte criativa. Procurava-se sempre organizar dessa forma, em diálogo com a proposta do dia de trabalho. No decorrer da prática, uma parte acabava sempre influenciando a outra, decorrente da progressão que acontece naturalmente dentro da pesquisa. $\mathrm{O}$ texto irá analisar a seguir essas partes de modo separado, a fim de aprofundar questões que podem ser necessárias para o entendimento do todo. 
O termo ensaio é empregado no trabalho como um espaço/tempo prático destinado à experimentação, voltado para o processo investigativo e criativo da atriz. Nesse sentido, o ensaio foi composto por exercícios de alongamento e aquecimento, que desembocavam e eram, ao mesmo tempo, parte da construção do todo. Quando é referido ao treinamento, dialoga-se diretamente com esses exercícios e com possibilidades de investigação que podem emergir através do contato com os mesmos.

Desse modo, os alongamentos e aquecimentos eram momentos de concentração e consciência de si e do espaço ao redor. O primeiro voltou-se para a abertura de espaços no corpo, para o trabalho com relaxamento e com a tonificação de alguns músculos, como uma preparação introdutória para que não houvesse nenhuma lesão. A insistência em algumas partes específicas, tais como a coluna, o aparelho fonador e o movimento das pernas, intentavam propiciar outras possibilidades de trabalho por meio do contato mais específico.

Durante os alongamentos o foco esteve direcionado para constantes linhas de oposições no corpo, com atenção para a coluna e a escuta. A tensão, neste caso, mantinha o corpo sempre consciente mediante uma propriocepção para direcionamentos ósseos e apoios, conceitos embasados na prática de Klauss Vianna (2005). O diálogo entre estes parâmetros foi tecido no intuito de se trabalhar com o tônus muscular, a fim de obter um movimento consciente ao longo do trabalho. Sobre isso discorre Jussara Miller:

A percepção de peso evidencia a dosagem do tônus muscular pois, quando eu me excedo na tensão da musculatura, a sensação de peso desaparece e, como consequência, a articulação se retrai. Quando eu doso a tensão na musculatura, equilibrando o tônus muscular, resulta numa sensação de leveza, com esforço adequado para executar o movimento, transformando assim, tensão muscular em "atenção muscular" (2007:65-66).

A tensão e a atenção durante os exercícios vinham concomitante a uma tentativa de manter consciente o movimento e o estado de prontidão do corpo. O alongamento era, deste modo, uma busca por estabelecer constantes diálogos com uma propriocepção e com uma relação com o meio. 
Realizou-se, assim, diariamente, uma sequência de movimentos, que tinha por base a respiração e a insistência em algumas posturas corporais. Esses movimentos são provenientes da Ioga e requerem uma concentração que condiciona o corpo para um estado de atenção diferente daquele que é utilizado cotidianamente.

Jerzy Grotowski em seu texto ‘O Encontro Americano’ (1968) se refere à pesquisa prática realizada no Teatro Laboratório (1959-1969), acerca de alguns exercícios da Ioga, salientando mudanças de expectativas em torno dessas atividades e da 'concentração introvertida' que ela poderia desencadear. Todavia, discorre também sobre seus benefícios e suas contribuições para o trabalho prático, criativo, dentre os elementos de contato:

\begin{abstract}
Mas observamos também que certas posições ioga ajudam muito as reações naturais da coluna vertebral; conduzem a uma segurança o próprio corpo, a uma adaptação natural no espaço. Então, por que não aproveitá-las? Começamos a pesquisar, a buscar os diferentes tipos de contatos nestes exercícios. Como poderíamos transformar os elementos físicos em elementos de contato humano? Representando com o próprio companheiro. Um diálogo vivo com o corpo, com o companheiro que evocamos em nossa imaginação ou talvez entre as partes do corpo cuja as mãos falam com as pernas, sem colocar este diálogo em palavras e pensamentos. Estas posições quase paradoxais vão além dos limites do naturalismo (1987, p. 195).
\end{abstract}

Os exercícios podem agir como um espaço destinado a ser explorado diariamente. Cada pessoa estuda as posições a seu modo, investiga seus contatos no corpo/espaço, para além de movimentos rígidos e sem liberdade de evasão. A prática visou desenvolvê-las, desse modo, na tentativa de trabalhar possibilidades de contato dessas posições com o corpo, com o espaço e com o processo investigativo e criativo de uma forma geral.

A partir da postura inicial, com as pernas esticadas, coluna solta ao longo do corpo, e a cabeça na direção dos pés, a atenção era direcionada para o relaxamento do tronco e soltura da respiração. A tensão se concentrava na altura do cóccix em direção ao teto, e nas pernas esticadas com os pés paralelos, maléolos para fora, em direção ao chão. Procurou-se, antes de realizar qualquer exercício vocal, focar inicialmente em um relaxamento do aparelho fonador, abertura da laringe, direcionada para respiração que podia 
ser trabalhada mediante esse jogo de tensões. Continuava a sequência de movimentação em nível médio, procurando manter constante o jogo de tensões no corpo. A noção de trabalhar-se a partir de níveis é desenvolvida com base nos estudos de Rudolf Laban. A ideia era sempre de relaxamento dos músculos, aliados posteriormente à contração voluntária dos mesmos.

Outra posição recorrente no trabalho é a pirâmide (quatro apoios, com o cóccix direcionado para cima, e movimentação de rotação da coluna e do quadril), possui grande atuação de forças contrárias, a favor de um alongamento e aquecimento do corpo. No decorrer da transição entre as posições, a movimentação pode dialogar com os elementos do céu e da terra qualidades de energia, ar e terra - ao passo que permanece em constante instabilidade entre essas forças, com o corpo sendo transferido de cima para baixo, auxiliado pelo processo respiratório.

Em contato com o chão, o alongamento continua com foco para coluna, e relaxamento do aparelho fonador. Esse último foi realizado no intuito de alongar e exercitar os músculos e cartilagens, da mesma maneira que as demais partes do corpo são estimuladas. As possibilidades de experimentação do aparelho fonador podem se tornar mais extensas, ao passo que ele é colocado no foco de investigação, contato e produção de desejo.

Outras duas posições importantes no nível baixo são: coluna completamente acomodada no chão, com as pernas para trás, em direção à cabeça; e a ponte, que é a inversão dos quatro apoios, com as mãos e pés posicionados no chão e o umbigo para cima, em direção ao céu. A primeira postura procura um relaxamento mais aparente do corpo, ainda que o abdômen esteja atuando mais efetivamente nesse momento, enquanto que a segunda pede uma tensão de forças constantes por conta da dificuldade empregada nessa posição.

A sequência procura desenvolver o alongamento concomitante a um aquecimento no corpo, por meio das linhas de tensões que podem ser criadas com essas posturas e as passagens entre elas. Há outras posições dentro do todo, igualmente importantes para a composição da sequência. Elas atuam 
não apenas como modelos de transição, mas de posicionamentos em constante desequilíbrio e tensão.

Desse modo, a voz sempre esteve presente durante os alongamentos, no intuito de explorar suas possibilidades dentro das posturas e jogos de tensões. Em torno de exercícios que proporcionassem uma constante abertura e relaxamento da laringe, foi investigado um som mais aberto, composto por vogais, durante os inícios de trabalho, para depois experimentar os aboios dentro do processo de aquecimento.

Em alguns momentos, quando a concentração estava mais direcionada desde o começo, a atriz procurava explorar essa sonoridade dos aboios ainda nas posições iniciais, para investigar esses sons mediante o jogo de tensões exigido pelo corpo.

Com o passar dos ensaios percebeu-se que algumas demandas apareceram como consequência da investigação vocal, demandas essas que não eram especificamente o foco da estrutura quando criada. Assim, a investigação norteou esses novos contatos e diferentes abordagens corporais em direção a outros caminhos ainda não explorados tão detalhadamente. Os aboios, muitas vezes, atuavam nesse território vocal, emanando uma abordagem distinta.

Me vi hoje enquanto sombra revestida de mato. Percebi ir por caminhos muito cômodos, compostos por movimentos ajustados e ritmos lentos. A sala estava clara demais, revelou o corpo magro e desajeitado, sem saber muito por onde ir.

Variei as ações iniciais em ordens diferentes. Do choro do meu boi nasceu a criatura. O som foi engolido, perpassando pelo corpo, por dentro da coluna, até parir o ser.

Como trabalhar o pesado a favor do sutil? A energia. Fiquei pensando nisso hoje.

Acho que o aquecimento está muito dançado, preciso me desconstruir mais. Quebrar com as minhas expectativas, meus vícios, caminhos sempre revisitados. ${ }^{4}$

Assim, em alguns dias de trabalho, a atriz mudou o que habitualmente acontecia para poder se concentrar apenas na sonoridade e nas

\footnotetext{
4 Trecho retirado do Diário de Bordo da atriz, Brasília, 25 de maio de 2016. As próximas inserções serão apresentadas a partir da sigla DB, que dizem respeito aos escritos realizados no decorrer do processo prático. Apresenta-se na formatação de citação direta, na tentativa de organizar os registros ao longo do texto.
} 
ações que desembocavam mediante essas relações. Alongava rapidamente em contato com o chão e seguia direto para os aboios, explorando diferentes frequências na voz, com durações distintas, várias vogais, algumas pequenas palavras em meio aos sons, e estabelecia-se pontos de contato concretos no espaço. Aboiava-se com diferentes ataques, entre sons interjectivos e pequenas variações tímbricas, permitindo estabelecer pontos concretos no espaço, em direção à árvore, aos pássaros, às pedras, e procurava investigar essa ressonância no corpo e no ambiente ao redor.

A necessidade veio com a prática, com a frustração de muitos ensaios, onde ela parecia estar fazendo sempre a mesma coisa, e não alçava voo para além do que já conhecia. A inquietação não se limitou apenas ao alongamento; partiu dele, a favor de um todo que desaguasse de maneira linear no processo criativo. Surge assim, da ideia de que tudo, gradativamente, é parte constituinte da cena, desde uma massagem nos pés ${ }^{5}$ como as pedras inseridas ao longo do processo. Do começo ao fim, a criação era vislumbrada.

As maiores dificuldades, no entanto, sempre se concentraram no aquecimento, pois era um momento do trabalho em que o corpo se encontrava em um estado de porosidade, excitador de sentidos e desejos, que podia ser facilmente induzido por caminhos já revisitados. Esse espaço intermediário do ensaio é direcionado para um trabalho específico com qualidades distintas de movimentos e energia. As investigações desses elementos propõem novos contatos com o corpo em diferentes situações do processo criativo ou, então, aprofundamentos em lugares percorridos outrora. A constante disputa de tensões iniciada no alongamento, aqui muitas vezes ganhava todo o ambiente. O ritmo podia ser mais rápido, o movimento maior, a fim de explorar esse corpo que se propõe rasgar pelas oposições e pelo espaço em relação direta com a escuta que aflora com o passar do trabalho. A coluna entra, como lugar disparador do movimento, da energia. O foco inicial é nela, em suas reverberações no corpo para o espaço e para além da voz.

$\mathrm{O}$ aquecimento pode ser visto como um território em constante movimento, que funciona como força motriz de elementos que serão

\footnotetext{
${ }^{5}$ Exercício recorrente dentro dos estudos de Klauss Vianna (2005).
} 
desenvolvidos ao longo da cena. Pensa-se que seja uma parte fértil desse processo criativo, pois é mediante o trabalho com distintas qualidades de energia e investigação de ações que o corpo se condiciona de outro modo para o que é proposto.

Ele segue a linha de pesquisa iniciada no decorrer do alongamento, a favor de uma consciência/potência corporal e criativa. Grotowski realça em seu texto 'O Treinamento do Ator' (1959-1962) a constante investigação dos movimentos dentro do processo, em função de um desenvolvimento psicofísico do artista, no início das pesquisas práticas do Teatro Laboratório com os exercícios físicos:

O exercício serve para a pesquisa. Não se trata de uma mera reprodução automática ou de um tipo de massagem/ muscular. Por exemplo, durante os exercícios deve-se investigar o centro de gravidade do corpo, o mecanismo de contração e de relaxamento dos músculos, a função da coluna nos diversos movimentos violentos, analisar qualquer desenvolvimento complicado e relacioná-lo ao conjunto de cada junta e cada músculo. Tudo isto é estritamente individual e resulta de uma pesquisa contínua e total. Somente os exercícios que "pesquisam" abrangem todo o organismo do ator e mobilizam seus recursos ocultos (1987, p.88).

Percebeu-se assim, a necessidade, atrelada ao treinamento, de possibilitar um corpo poroso, sensível e atento. Esses pilares sustentam uma gama de contatos consigo mesmo e com o espaço, os quais procuram tecer a criação e o jogo em cena. Eles vêm, desse modo, aliados aos elementos concretos do espaço, como um meio de enfatizar uma relação real com o meio, e com a ação.

Alguns dos exercícios utilizados para adentrar esse campo do aquecimento partiam das posições finais da sequência de alongamento. As tensões que formavam as posições corporais se concentravam na maleabilidade da coluna nesse momento do exercício. Já de pé, em nível alto, a movimentação acontecia através de um jogo no tronco, próximo a movimentos ondulatórios, dialogando com as seguintes imagens: chicote na coluna; o tronco composto por correntes de ar; serpente na coluna. A precisão é dada pelo olhar, no chicotear do movimento em direção a um ponto fixo externo. Variava assim as qualidades dentro do exercício, bem como os 
lançamentos vocais que poderiam ser experienciados a partir dos lançamentos com a coluna.

'Da coluna parte meu desejo de rasgar a carne e ser espaço. A nuca aguça os ouvidos e proporciona uma atenção outra para o corpo.' ${ }^{6}$ A busca pelo equilíbrio entre os pés firmes no chão e a maleabilidade do tronco era constante. As ações que emergiram desse jogo nasceram da exploração sonora de um corpo, que já iniciou o processo criativo com outra energia em busca de uma atenção constante para as sutilezas provenientes dessas qualidades de movimento.

III. Os aboios e suas reverberações na prática

A transição e investigação dos exercícios estudados ao longo do aquecimento, para as situações e ações de cenas, compõem uma linha tênue. Podem aparecer como potentes, pois transitam nesse lugar de pesquisa do exercício, já exposto também através de uma citação de Grotowski, de seu texto 'O Encontro Americano'. A criação reverbera nesse espaço do entre, onde a técnica é visada a favor de um aprofundamento, e de uma consciência e desenvolvimento do trabalho da atriz.

O que não é visível, audível, tateável, pode ser degustado e cheirado na porosidade do corpo que já foi revirado inicialmente, na tentativa de se apresentar acordado para o processo criativo com os aboios. É ser atuante e, ao mesmo tempo, ser levada. Sobre essa maneira de olhar e estar no processo, coloca Grotowski:

Que é que desimpedirá as possibilidades naturais e integrais? Agir - isto é, reagir não conduzir o processo mas relacioná-lo com experiências pessoais, e ser conduzido. O processo deve nos possuir. Nestes momentos, devemos ser internamente passivos, mas externamente ativos. A fórmula de resignar-se a "não fazer" é um estímulo (1987, p. 191-192).

A intenção, então, além de se apropriar cada vez mais desses exercícios, foi deixar com que a criação alçasse voo. As associações com

${ }^{6}$ DB, Matão, 22 de julho de 2016. 
imagens e experiências pessoais se tornaram mais frequentes com o decorrer do processo.

Parte-se do exercício de lançamento inicialmente apresentado, com variações rítmicas e movimentações compostas por diferentes qualidades de energia na coluna. Visou-se seu estudo técnico a fim de pesquisar diariamente peculiaridades das qualidades de movimentos e possibilidades de aprofundamento do mesmo. A exploração se tornava mais precisa, ao passo que a voz ganhava o espaço de experimentação e compunha, assim, mais um meio de expressão.

A pesquisa que teve início na sequência de alongamento e perpassou para o aquecimento, era composta por sonoridades, estimuladas pelos contatos com os aboios e com os sons inicialmente ouvidos, por meio dos áudios da Missão de Pesquisas Folclóricas. Deste diálogo algumas ações surgiram e foram investigadas no decorrer do processo: ver, carregar, caminhar e escutar. Elas compunham e, ao mesmo tempo, se tornavam um mapa de pesquisa tridimensional, com movimentos e intenções pontuadas no espaço.

A noção de ação dentro da pesquisa dialoga com a ideia de ação física desenvolvida por Grotowski ao longo de suas práticas. O intuito não é abordar esse conceito de maneira exaustiva, mas tecer reflexões com base em análises de alguns teóricos. Mario Biagini coloca em seu texto 'Sobre o Cultivo das Cebolas' (2013) algumas considerações acerca das 'atividades' e das 'ações físicas':

\begin{abstract}
As atividades (procurar pelo maço para evitar o contato com vocês, abri-lo cerimoniosamente para recuperar-me de seu ataque, escolher cuidadosamente um cigarro para encontrar rapidamente uma resposta que me salvará) adquirem, então, outra dimensão: elas estão conectadas umas às outras por uma intenção, que é motivada, digamos, por um desejo. Elas se desenvolvem em relação a alguma coisa ou a alguém fora de mim, elas se desenvolvem em um espaço que não é estéril, o espaço do contato. Elas não existem em si e por si mesmas. Em certo sentido, elas têm um alvo e podem, portanto, tornar-se ações físicas (RICHARDS apud BIAGINI, p. 301)
\end{abstract}

Salienta-se, nesse caso, a construção que é entrelaçada com base na relação, 'a alguma coisa ou alguém fora de mim', como prática almejada 
dentro do processo, na tentativa de estabelecer diálogos mais claro com a parte criativa. Continua Biagini:

[...] quando estruturamos um fragmento de ação de modo que sejamos capazes de repeti-lo e aprofundá-lo, geralmente, e nem mesmo na fase inicial, nós não separamos um aspecto formal de um aspecto interno: nós estruturamos quase exclusivamente intenções, associações, impulsos (2013, p. 302).

As ações vieram por meio do contato com as sonoridades, com objetos utilizados ao longo da criação (pedras e galhos) e os exercícios já citados. A dificuldade estava atrelada às imagens que surgiam ao longo do processo, bem como a possibilidade da atriz estar calcada mais nas 'atividades' do que nas ações físicas em si. Essas, por sua vez, compostas e nutridas por esses espaços de contato, se tornavam um território de difícil acesso, ao passo que na maioria das vezes a atriz se encontrava sozinha em sala e as conexões eram muito voltadas ao meio. Desse modo, o receio em conduzir demais essas relações acabavam prejudicando a experimentação e a criação do todo.

Assim, o movimento da coluna era reverberação dos exercícios desenvolvidos no aquecimento e união com o ato de chamar os bois. A atriz não conseguia experimentar ambos separadamente, sem estar nessa conexão que foi se costurando com o decorrer dos ensaios. Aos poucos, algumas palavras foram inseridas, 'e boi'; com saltos na voz; ela procurava chamar os bois, jogava com as pedras que existiam em cena e com tudo que de alguma maneira pudesse ajudar nessa comunicação direta, o ato de chamar, de se comunicar com algo real.

Os aboios, as atividades dos marroeiros, possuem registros que foram apontados desde tempos muito remotos, como apresentado ao longo do artigo. Podem carregar especificidades da manifestação de maneira geral, de forma que consegue-se reconhecer esta sonoridade através de algumas aproximações entre elas, como o tom melancólico, que poderia ser talvez um exemplo levado em consideração. Todavia, o que ficou mais saliente foram as singularidades que em seus desejos, vontades, bloqueios e medos, se faziam 
presentes enquanto força propulsora que cresce e faz germinar, a cada dia, o contato destes seres humanos com o meio e os animais.

A ação de comunicar pareceu fazer mais sentido quando os ensaios foram para um espaço aberto. No entanto, notou-se a importância dos momentos sozinha como um período de investigação da sonoridade no corpo, como algo íntimo. A atriz, gradativamente, observou como o espaço também ajudou a investigação com seus registros dos aboios; queria assim, que o som tivesse traços seus, a fim de investigar as reverberações dele no corpo e no espaço enquanto ação.

Nesta pesquisa chegou-se, então, a uma posição inicial. Com as costas um pouco encurvadas e as mãos segurando um galho seco, o aboio é entoado. Nesse momento é como se ela chamasse um boi específico e, ao mesmo tempo, fosse ele. $\mathrm{O}$ direcionamento estava no corpo, pois durante os experimentos com o aboio - quando iniciava nessa posição de costas ao ponto de referência, onde se colocaria o espectador -ela ao mesmo tempo que chamava o boi, também flertava com a ideia de ser esse animal. Era o boi que escutava e respondia ao canto.

O galho, nesse caso, se colocava como um prolongamento do corpo, um pedaço do animal, uma ferramenta utilizada pelo vaqueiro. É o carregar do objeto, ver o ser chamado, caminhar e, ao mesmo tempo, escutar e ser o canto. De alguma maneira o galho estava em cena como um elemento que vem somar, dentro do todo, a favor da constituição de significados durante a construção da ação.

O som também dispara um jogo de impulsos na coluna, ele que a faz sair do lugar e se mover a partir do canto. A repetição parece dilatar esse estado e procura, ao mesmo tempo, insistir na ação de chamar o animal e o ser, concomitantemente. Fica ainda mais forte a ação/contato/energia do canto que gera mudança. Não se escuta apenas com as orelhas, o corpo todo está engajado no ato de chamar e responder. 
Parte-se neste momento de uma posição corporal, que surgiu através da investigação desta sonoridade no corpo, a fim de saber se, e como este material pode se tornar força poética. Dessa maneira, a pesquisa a encaminhou para duas figuras corporais: uma velha e uma criança. Utilizouse essa terminologia por não serem necessariamente personagens, atuam quase como esboços tridimensionais, por meio de ações. Elas podem compor um campo mais vasto, que não necessariamente foca em uma pessoa que tenha uma história para se apresentar. Estão assim presentes naquele momento.

Quando do corpo que chama o boi surge o animal, o esgarçar dessa imagem sugeriu a corporeidade de uma velha. $\mathrm{O}$ detalhamento do trabalho com a articulação dos pés, no decorrer de uma pequena caminhada que é iniciada, joga com essa condição corpórea e alia o risco à sabedoria. É como se chegasse a vários cantos do corpo, a memórias guardadas e/ou esquecidas, detentoras de lembranças que podem ser despertadas. A precisão que essa imagem/corpo estabelecia parecia, ao mesmo tempo, definir a ação e torná-la mais precisa. $\mathrm{O}$ corpo, os impulsos e a energia desse momento fazia a atriz reviver memórias com a sua avó. Vieram imagens das veias saltadas nas mãos, a confusão da memória no final da vida e as tonalidades da pele.

A sonoridade sai como se fosse uma lamúria, o aboio que é um choro, um grito, um chamado. Na solitude do trabalho, a atriz procurou estabelecer a todo momento contatos concretos para não se perder no processo de criação.

E a criança que surgiu partiu de uma ação corporal que se iniciou com as pedras. Foi denominada de voz larva - o bicho - algo ainda sem muita forma, e com uma sensação de potência.

Ela se relaciona ao aboio, pois diz desse ser que nasce do mato, que se comunica pelos sentidos primeiros do corpo, o escutar atento e perceptivo. Os instintos estão assim, mais aguçados.

$\mathrm{E}$ das raízes chega-se à semente, da velha à criança. Um estado semente, algo aparentemente cíclico e primordial. É como se o processo de 
criação tivesse a abertura para revelar algo deveras primordial, e a artista, com o amadurecimento do trabalho, chegasse ao ponto de começar a compreender o fluxo proposto, com a intenção de pesquisar um aprofundamento de si. Trabalhar muito sobre pouco; em raízes - o estado semente é germinativo. $\mathrm{O}$ papel em branco onde a memória será rabiscada.

A perspectiva traçada foi apenas uma dentre tantas outras possíveis. A intenção foi criar e ser poesia, mediante algumas imagens, ações, lembranças em contato vivo com sonoridades que fazem parte de culturas brasileiras.

É na escuta atenta que a relação pode ser tecida. O tempo, o espaço, o outro entram como pontos de contatos concretos, no auxílio constante de um trabalho que vai em direção ao exterior, que pode dizer de si, em função de um crescimento que não se estanca no corpo que ressoa.

$$
* * *
$$

\section{REFERÊNCIAS}

ANDRADE, Mário de. As Melodias do Boi e outras Peças. São Paulo: Duas Cidades, 1987.

ANDRADE, Mário de. Dicionário Musical Brasileiro. Coordenação: Oneyda Alvarenga, 1982 - 84, Flávia Camargo Toni, 1984 - 89. São Paulo: EDUSP, 1989.

BIAGINI, Mario. Encontro na Universidade de Roma "La Sapienza" ou Sobre o Cultivo das Cebolas. Porto Alegre: Revista Brasileira de Estudos da Presença, $n^{\circ}$ 1, UFRGS, 2013, p. 287-332.

GROTOWSKI, Jerzy. Em Busca de um Teatro Pobre. Rio de Janeiro: Civilização Brasileira, 1987.

GROTOWSKI, Jerzy. FlASZEN, Ludwik; BARBA, Eugênio. O Teatro Laboratório de Jerzy Grotowski 1959 - 1969. São Paulo: Perspectiva, 2010. 
LABAN, Rudolf. Domínio do Movimento. São Paulo: Summus editorial, 1978. LIGNELLI, César. Sons e (m) cena. Brasília: Dulcina, 2014.

LIMA, Cristiane da Silveira. Ê gado manso! Ê , saudade! Uma travessia com o filme Aboio. Belo Horizonte: Revista Devires, $n^{\circ} 2$, v. 11, UFMG, 2014, p. 74-97.

MAURÍCIO, Maria Laura de Albuquerque. Aboio, o canto que encanta: uma experiência com a poesia cantada na escola. 96 f. Dissertação (Mestrado em Letras) - Centro de Ciências Humanas, Letras e Artes, Universidade Federal da Paraíba, João Pessoa, 2006.

MENDES, Caçula Adriano. Aboio no Sertão Paraibano: Um canto no trabalho, um trabalho no canto. 132 f. Dissertação (Mestrado emMúsica) - Programa de Pós Graduação em Música, Universidade Federal da Paraíba, João Pessoa, 2015.

MILLER, Jussara Corrêa. A Escuta do Corpo: sistematização da Técnica Klauss Vianna. São Paulo: Summus, 2007.

VIANNA, Klauss. A Dança. São Paulo: Summus, 2005.

WISNIK, José Miguel. O Som e o Sentido. São Paulo: Companhia das Letras, 1989.

Filmes

ABOIO. Direção: Marília Rocha, Produção: Helvécio Marins Jr. e Marília Rocha. Brasil: Anavilhana Filmes LTDA - ME GNCTV - Produções de Cinema e TV LTDA, 2005. 73min.

Recebido em agosto de 2018. Aprovado em outubro de 2018. Publicado em dezembro de 2018. 